42

Community: Volume 4, Nomor 1, April 2018

ISSN: 2477-5746

\title{
MEMBACA MASYARAKAT ACEH MELALUI PUJIAN DALAM SYAIR TARIAN RAPA'I
}

\author{
Cut Irna Liyana \\ Dosen Tetap Sosiologi, Universitas Teuku Umar \\ Email: cut.irnaliyana88@gmail.com
}

\begin{abstract}
The use of language in a society can reflect the culture of one society. The aim of this study is to describe the Acehnese culture and perspective about compliment throught Syair of Rapa'I Dance. This is a qualitative research. Compliments in Syair of Rapa'I Dance are data in this research. To collect the data, researcher do observation and to analyze the data, interpretative method is used. The result shows that, compliment on Rapa'I's dance shows that in the Rapa'I Aceh, compliment is generally addressed to God. This is because the Acehnese culture that puts forward the values of Islam so that compliment as praise that exists is only aimed at God.
\end{abstract}

Key words: compliment, language, society

\section{PENDAHULUAN}

Bahasa dan masyarakat adalah dua komponen yang saling mengikat dan tak dapat dipisahkan. Penggunaan bahasa dari suatu masyarakat tertentu dapat menunjukkan atau mencerminkan kelas sosial masyarakat tersebut. Demikianpula hubungan bahasa, masyarakat dan kebudayaan. Bahasan terkait bahasa dan masyarakat tidak pernah terbebas atau terlepas dari kebudayaan yang ada dalam suatu masyarakat. Layaknya hubungan bahasa dan masyarakat, hubungan bahasa dan kebudayaan juga tidak dapat dipisahkan. Bahasa turut dipengaruhi oleh budaya yang ada dalam suatu masyarakat. Sehingga, apa yang ada dalam kebudayaan akan tercermin dalam bahasa setempat.

Salah satu budaya masyarakat yang berbentuk tindak tutur adalah budaya memuji. Memuji merupakan salah satu cara yang dapat dilakukan untuk menyenangkan hati lawan bicara. Dengan memuji, lawan bicaraakan merasa senang dan komunikasi dapat berjalan dengan baik. Memuji berasal dari kata puji yaitu pengakuan rasa kekaguman dan penghargaan yang tulus akan kebaikan (keunggulan) sesuatu. Kata-kata pujian adalah kata-kata yang dituturkan sebagai tanda senang, rasa hormat, rasa takjub, dengan istilah- 
Community: Volume 4, Nomor 1, April 2018

ISSN: 2477-5746

istilah atau penamaan tertentu yang sangat menyenangkan dan membanggakan. Memuji merupakan tindak bahasa yang menerapkan prinsip kesopanan berbahasa. Memuji merupakan salah satu contoh tuturan yang sejalan dengan maksim penerimaan. Leech (1983) terkait dengan prinsip kesopanan menyatakan bahwa prinsip kesopanan meliputi maksim kebijaksanaan (tact maxim), maksim kemurahan (generosity maxim), maksim penerimaan (approbation maxim), maksim kerendahan hati (modesty maxim), maksim kecocokan (agreement maxim), dan maksim kesimpatian (sympathy maxim).

Setiap masyarakat memiliki cara tertentu dalam memuji bergantung kepada budaya dan adat istiadatnya. Setiap anggota masyarakat tutur terikat oleh nilai-nilai sosial dan nilai-nilai budaya masyarakatnya, termasuk nilai-nilai ketika menggunakan bahasa. Hal ini sejalan dengan yang dikatakan oleh Wierzbicka dalam Handbooks of Pragmatics (2010: 3) bahwa setiap orang yang hidup dengan bahasa yang berbeda di budaya yang berbeda maka akan melahirkan konsep budaya yang berbeda.

Wieland (1995) dalam penelitiannya membandingkan perilaku memuji pada budaya Prancis dan Amerika. Penelitiannya mengungkapkan bahwa orang Prancis cenderung lebih sering memuji dibandingkan orang Amerika. Selanjutnya, Wolfson (1981) membandingkan perilaku memuji dari berbagai perspektif budaya, yaitu Amerika, Indonesia, Jepang, Prancis, Iran dan Arab.

Selanjutnya, Wolfson (1981) secara khusus mengemukakan bahwa pujian dipandang berbeda dari satu masyarakat dengan masyarakat lainnya. Dalam penelitiannya ini, iamendeskripsikan struktur semantik dan sintaksis pujian dalam bahasa Inggris Amerika dan membandingkan perilaku memuji di budaya yang berbeda. Data dikumpulkan dalam corpus berupa pujian dari non-penutur asli bahasa Inggris yang berinteraksi dengan komunitas tutur baik dalam bahasa Inggris dan bahasa pertamanya. Beberapa data membuktikan bahwa terdapat perbedaan oleh penutur ketika mempersepsikan pujian. Pujian pelajar Indonesia sering dianggap bukan sebagai pujian oleh budaya Amerika. Hal ini dikarenakan pujian jarang ditemukan di budaya Indonesia, pujian hanya terdapat pada orang-orang berpendidikan dan yang sudah terpapar budaya barat. Penutur Jepang, cenderung memuji penampilan orang lain yang dihubungkan dengan materi atau uang. Aturan tuturan seperti ini sulit diterima oleh penutur Amerika. Perbedaan persepsi juga terdapat di Iran dan Arab, yang cenderung menggunakan ungkapan untuk memuji.

Pada artikel ini, penulis ingin melihat fenomena budaya memuji yang ada di Aceh. Aceh merupakan salah satu wilayah di Indonesia yang memiliki aneka ragam budaya yang menarik khususnya dalam bentuk tarian, kerajinan dan perayaan/kenduri. Aceh, juga memiliki budaya yang berbeda dengan daerah lainnya. Menurut pengamatan penulis, orang Aceh cenderung jarang memuji orang lain, kecuali orang-orang yang memiliki status pendidikan yang tinggi dan sudah terpapar budaya luar. Apakah konsep memuji tidak terdapat di budaya Aceh? sehingga pujian yang ditujukan untuk lawan 
44

Community: Volume 4, Nomor 1, April 2018

ISSN: $2477-5746$

bicara sulit ditemukan. Rasanya terlalu dini menyimpulkan bahwa tidak terdapat konsep memuji dalam budaya Aceh. Mengingat Aceh dikenal dengan adat "peumulia jamee" (memuliakan tamu) dan juga banyak terdapat karya seni yang berisikan pujian.

Berdasarkan hal tersebut, penulis tertarik mengkaji penggunaan pujian dalam syair tari rapai Aceh. Syair tari Rapa'I dipilih karena kehidupan masyarakat dapat dilihat dari hasil kebudayaannya. Sehingga, penulis ingin melihat cara pandang orang Aceh terhadap pujian melalui karya seni budayanya khususnya syair tari Rapa'I.

\section{TINJAUAN PUSTAKA}

Pujian berarti pernyataan memuji (KBBI). Pujian berbeda dengan penilaian. Penilaian tidak berarti pujian, tetapi pujian termasuk penilaian. Penilaian berkaitan dengan pernyataan evaluasi kualitatif terhadap sesuatu. Penilaian bisa menunjukkan hasil yang positif atau negatif, sedangkan pujian bertalian dengan penyataan positif terhadap sesuatu atau seseorang. Dalam norma bahasa masyarakat pujian merupakan kata-kata yang dipandang baik bagi penutur dan mitra tutur dan bertujuan untuk menciptakan solidaritas dan harmonisasi. Pujian dalam tindak tutur menduduki fungsi sebagai tindak tutur ekspresif, yaitu tindak tutur yang dimaksudkan penuturnya agar ujarannya diartikan sebagai evaluasi tentang hal yang disebutkan di dalam tuturan itu.

Penelitian mengenai pujian (compliment) pernah dilakukan oleh beberapa peneliti yaitu, Valdes dan Pino (1981), Holmes (1986), Rose (2001), Dus (2001), Golato (2002), Chen (2010), Cheng (2011), Guo, Zhou dan Chow (2012) serta Ricahyono (2016). Rose (2001) melakukan penelitian dengan objek kajian film. Penelitian berjudul "Compliment and Compliment Responses in film: Implication for Pragmatics Researsh and Language Teaching" ingin mengetahui bagaimana film merepresentasikan komunikasi manusia dalam kenyataan. Penelitian ini mengambil data dari pujian dan respon pujian yang berasal dari 40 film Amerika.

Valdes dan Pino (1981), Dus (2001), Golato (2002), dan Cheng (2011) meneliti mengenai respon pujian dengan membandingkan dua bahasa. Valdes dan Pino (1981) melakukan penelitian mengenai respon pujian yang terdapat dalam komunikasi antara penutur bilingual Meksiko dan Amerika. Golato (2002) meneliti pujian dengan judul "German Compliment Responses". Penelitian ini membandingkan respon pujian yang dilakukan oleh penutur bahasa Jerman dan penutur bahasa Inggris-Amerika. Dus (2001) meneliti pujian mahasiswa Inggris dan Spanyol sedangkan Cheng (2011) meneliti tentang respon pujian yang 8 diproduksi oleh penutur bahasa Inggris dan penutur asli bahasa Cina yang berbahasa Inggris.

Holmes (1986) meneliti tentang pujian dan respon pujian di New Zealand. Penelitian ini melihat fungsi, tindak tutur, prinsip kesopanan berbahasa, dan perbedaan budaya 
(cross-cultural) dalam kebiasaan memuji. Penelitian tersebut menggunakan data sebanyak 500 tuturan pujian yang dianalisis dengan menggunakan teori sintaksis dan karakteristik bentuk leksikal pujian serta fungsi dari kategori pujian dan respon pujian di masyarakat New Zealand. Penelitian ini juga melibatkan adanya hubungan status sosial antara penutur dan mitra tutur dalam memuji dan merespon pujian. Data penelitian dikumpulkan dari siswa di New Zealand. Pemuji pada umumnya adalah orang pakeha dewasa di New Zealand dan yang menjadi fokus penelitian adalah aturan dalam memuji pada kelompok ini. Holmes menggunakan metode kualitatif dan kuantitatif. Pembahasan mengenai pujian diidentifikasi dengan menggunakan struktur kalimat. Konstruksi kalimat diidentifikasi berdasarkan kelas kata yang 9 membentuknya. Penelitian ini menemukan frekuensi kemunculan kategori adjektif pujian yang dianalisis secara kuantitatif. Kemunculan adjektif pujian yang paling banyak berturut-turut adalah nice, good, lovely, beautifull, great, neat, wonderfull, delicious, pretty, new, smart, gorgeous, not bad, clever, bright, brilliant, excellent, fantastic, fine, cute, classy, cool, and impressive. Penelitian membandingkan kemunculan kata sifat like dan love yang terdapat $90 \%$ dari data New Zealand dan 86\% dari data Amerika. Selanjutnya, pembahasan mengenai respon pujian menghasilkan tiga kategori atau tipe respon pujian, yaitu accept (menerima), reject (menolak), dan deflect/evade (mengalihkan).

Guo, Zhou dan Chow (2012) melakukan penelitian dengan judul "A Variationist Study of Compliment Responses in Chinese". Penelitian ini menerapkan kajian sosiolinguistik dan pragmatik dengan korpus data sebanyak 1190 data tuturan natural pada komunitas tutur di Shanghai. Terdapat beberapa strategi merespon pujian yang dilakukan oleh komunitas tutur di Shanghai dengan adanya perubahan konsep kesopanan berbahasa. Respon pujian dihubungkan dengan variasi sosial mulai dari gender, usia, status sosial, pendidikan, kelas sosial, jarak sosial, dan adanya penggunaan bahasa Inggris.

Selanjutnya adalah penelitian Ricahyono (2016) berupa disertasi yang berjudul "Javanese Compliment-Paying and Compliment Responding: A Cultural Discourse Approach". Disertasi ini bertujuan untuk menganlisis dan menjelaskan secara budaya, pujian dan respon terhadap pujian dalam Bahasa Jawa. Fokus dari pujian/CP adalah:1)struktur semantik, dan2) topik. Respon pujian ditujukan untuk mengungkap pola-pola strategi Makro dan Mikro yang disukai dan yang kurang disukai. Data penelitian ini adalah 745 pasang pujian dan respon pujian yang direkam secara audio berupa data natural yang diambil dari berbagai macam interaksi. Participan dalam penelitian ini adalah laki-laki dan perempuan, anak-anak, remaja dan dewasa yang bertempat tinggal diwilayah kantung budaya Jawa Mataraman yang meliputi Madiun, Ngawi, Magetan, dan Ponorogo. Data dianalisis secara kualitatif. Tetapi deskriptif kuantitatif diberikan untuk perbandingan antar budaya. Topik CP terdididari:1) 
46

Community: Volume 4, Nomor 1, April 2018

ISSN: 2477-5746

Kemampuan/Ability(AB), 2)Penampilan/Appearance(AP), 3) benda- benda milik/Possession(PO), 4) watak atau kepribadian/Personality(PS), dan 5) Lain-lain/Others (OT). Strategi Makro dalam Respon pujian (CR) terdiri dari diterima/Acceptance(ACC), ditolak/Rejection(RJC), dan dihindari/Evasion(EVS). Hasil menunjukkan bahwa CP dalam Bahasa Jawa sangat terstruktur. Secara Semantik, CP sebagian besar diungkapkan dengan hanya menggunakan: kata sifat (ADJ), kata keterangan/amplifiers(AMP), kataseru/interjections (INT). ADJapik muncul paling sering. ADJ tingkatan biasa (positive) juga paling sering muncul. Strategi Makro ACC, RJC dan EVS muncul seimbang, tidak ada yang dominan. Nalar Jawa sakmadya, selaras, dan adhap asor menjadi penjelasan realisasi ADJ positive degree dan sebaran merata ACC, RJC dan EVS tersebut. Sakmadya, selaras, dan adhap asor menolak pilihan-pilihan ekstrim. Strategi Mikro' menasihati' (AS) menjadi khas dalam merespon pujian Jawa. Ini didasari oleh nilai budaya loma yaitu suka memberi. Strategi Mikro' bersyukur kepadaTuhan' (TG) jugamenjadikhas dalam merespon pujian Jawa. Hal inidilandasi oleh tradisi masyarakat Jawa slametam, kenduren, dan bancakan yang merupakan ritual ungkapan syukur kepada Tuhan.

\section{METODE PENELITIAN}

Metode merupakan cara memahami masalah penelitian. Metode menjabarkan cara yang harus ditempuh peneliti dalam setiap penelitian (Sudaryanto, 1993:25). Penelitian ini termasuk penelitian deskriptif, yaitu penelitian yang didasarkan pada fakta yang ada atau fenomena yang secara empiris hidup pada penutur-penuturnya sehingga hal yang dihasilkan merupakan paparan apa adanya. Penelitian ini dilakukan dengan tiga tahapan, yaitu 1) pengumpulan data, 2) analisis data, dan 3) penyajian hasil analisis data.

1) Metode Pengumpulan data

Sumber data dalam penelitian ini merupakan sya'ir lagu tari Rapa'I Aceh yang mengandung pujian oleh penutur bahasa Aceh. Metode yang digunakan dalam pengumpulan data yaitu metode simak dengan teknik catat. Mahsun (2007:242) mengemukakan bahwa metode simak merupakan metode yang digunakan dalam penyediaan data dengan cara penyimakan penggunaan bahasa oleh peneliti. Metode ini dapat disejajarkan dengan pengamatan atau observasi. Dalam penelitian ini, peneliti menyimak teks sya'ir lagu Rapa'I Aceh yang mengandung pujian dalam bahasa Aceh. Selanjutnya dilakukan klasifikasi atau pengelompokan data yang mengandung pujian. Peneliti akan menyimak dan mencatat data yang ada sesuai dengan kebutuhan dalam penelitian ini. 


\section{2) Metode Analisis Data}

Mahsun (2007:253) menegaskan bahwa analisis data merupakan upaya yang dilakukan untuk mengklasifikasikan dan mengelompokkan data. Sejalan dengan pernyataan tersebut, dalam penelitian ini dilakukan dua tahapan analisis data. Pertama, dilakukan pengidentifikasian terhadap data, yaitu mengidentifikasikan bentuk-bentuk pujian yang terjadi. Kedua, dari hasil identifikasi tersebut dilakukan pemilahan untuk membuat klasifikasi data. Selanjutnya, analisis data akan dilakukan dengan metode interpretasi. Penulis melakukan penafsiran terhadap budaya masyarakat melalui data yang ada.

3) Penyajian Hasil Analisis Data

Berdasarkan klasifikasi dari data yang ditemukan, hasil analisis akan disajikan dalam bentuk deskripsi. Hal ini karena penelitian yang dilakukan merupakan kajian kualitatif. Selanjutnya, hasil penelitian dijelaskan dalam uraian. Penyajian hasil analisis data dalam penelitian ini tersaji dengan kata-kata. Hal ini sejalan dengan Mahsun (2007:123) yang menegaskan bahwa hasil analisis yang berupa kaidah-kaidah dapat disajikan melalui dua cara. Salah satu dari metode tersebut adalahmetode formal yang perumusannya dengan menggunakan kata-kata biasa, termasuk penggunaan terminologi yang bersifat teknis.

\section{PEMBAHASAN}

\section{A. Tindak Tutur Memuji}

Memuji adalah tindak tutur yang secara langsung atau tidak langsung memberikan penghargaan kepada seseorang selain penutur, biasanya petutur atas beberapa "kelebihan yang dimilikinya, seperti kepunyaan keahlian, dan lain-lain.tindak tutur yang secara langsung atau tidak langsung memberikan penghargaan kepada seseorang. Jadi, tindak tutur memuji adalah tindakan melakukan pujian yang dilakukan seseorang (penutur) terhadap orang lain (petutur). Brown dan Levinson (dalam Holmes, 2003:177) memaparkan bahwa pujian adalah contoh utama tindak tutur yang memperhatikan dan mengikuti minat (interest), keinginan (wants), kebutuhan (needs), dan penampilan (goods) petutur. Brown dan Levinson juga menyatakan bahwa pujian merupakan strategi kesantunan positif. Dalam kajian ini, pujian yang akan dikaji adalah pujian yang terdapat dalam syair tarian Rapa'I Aceh.

\section{B. Tarian Rapa'i Aceh}

Rapai merupakan salah satu kesenian tradisi Aceh. Rapai dibawa dari hasil kebudayaan Timur Tengah melalui India pada abad XIII yang kemudian menjadi media 
48

Community: Volume 4, Nomor 1, April 2018

ISSN: 2477-5746

dakwah dalam penyebaran agama Islam di Aceh. Pada masa kerajaan Islam pertama pertunjukan Rapai membawa pengaruh budaya yang berkembang menjadi suatu bentuk kesenian. Rapai mempunyai fungsi sosial budaya pada masa pemerintahan kerajaan Islam di Aceh yang pada saat itu dipimpin oleh Sultan Iskandar Muda. Penyebaran Islam melalui alat musik Rapai berawal dari seorang Ulama besar Islam yaitu Syekh Abdul Qadir Zailani yang meneruskan ajaran Islam dari seorang Ulama Ahli tasawuf dari Baghdad Irak yang bernama Syekh Ahmad Rifa'I (Murtala 2009: 34). Pertunjukan Rapai dimainkan oleh laki-laki dengan jumlah pemain antara 8 sampai lebih dari 12 orang. Pada awal diciptakannya kesenian ini biasanya ditampilkan oleh laki-laki dewasa. Namun, dalam perkembangannya saat ini kesenian Rapai banyak dimainkan oleh anak-anak dan remaja hal ini disebabkan karena gerakannya yang atraktif dan menyenangkan.

Rapai memiliki 3 babak yaitu: Saleuem (salam), Kisah (baik kisah rasul, nabi, raja, dan ajaran agama) dan Lani (penutup). Pertunjukan Rapai merupakan salah satu dari bentuk kesenian yang merupakan wujud kebudayaan hasil olah pikir, ide ataupun gagasan masyarakat Aceh. Rapai digunakan sebagai media dakwah agama Islam yang memiliki rasa keindahan (estetika) yang ditimbulkan dari gerak, syair dan musik. Setiap komponen terdapat kearifan lokal yang memiliki makna, isi pesan tentang norma-norma sosial, nilai-nilai budaya dan sebagai wujud kebudayaan yang mengatur sistem sosial dalam menata aktivitas kehidupan sosial masyarakatnya.

Adapun contoh syair tari Rapa'I adalah sebagai berikut:

Masalah donya masalah donya mangat-mangat bak ta eeh

Bantai meutindeh bantai meutindeh ngon suprei-suprei sutra

Oh watee matee oh watee matee lam bumo-bumo ta eeh

Tanoh geutindeh-geutindeh bungong-bungong keureunda

Huda roh huda roh muttolak-muttolak ya Ilallahu zat muttolak

Ruhul kudus su ruanuri ibanil ibanillahi zat muttolak

Assalamualaikum....

Hai aneuk hai aneuk nanggroe....

Salam bak kamoe su'ot beurata...

Wa'alaikum salam....

Hana hai kamoe meuharta yang meukon droe

Lah na tuboh droe nyang na kamoe mee

Jaweub bri saleum Nabi keun sunah

Jaroe tamumat syarat meulia... 
Mulia wareh Ranub Lampuan

Mulia rakan beumameh haba...

Alhamdulillah pujoe bak Tuhan Nyang peujeut Alam Langet ngon Donya

Teuma seulawet ateuh Muhammad Pang ulee alam Rasul Ambia

Allahu Allah Allahu Rabbi Bek dilee neubrie kiamat donya

Umat lam donya lethat kesalahanTingai sembahyang dengan puasa

Dilaot Aron meupuloe peurahoe woe dua-dua

Hai rakan bek lee laloe budaya droe

Beugot ta jaga.

Hom hai le hala baguna hom hai le hala

Bismillah Alhamdulillah ya Allah Nyang poe Kuasa

Seulawet keu Rasulullah ngon Lidah beutatem baca

Allahu Allah Allahu Rabbi Allah hadiron nyang Maha Suci

Masa cut Nabi didalam ayon Rahmat geupeutron oleh Nabi

C. Tafsir Budaya Terhadap Pujian dalam Syair Tari Rapa'i Aceh

Berdasarkan syair tari rapa'I Aceh di atas, bahwa terdapat beberapa pujian yang akan dipapar berikut ini:

[1]Huda roh huda roh muttolak-muttolak ya Ilallahu zat muttolak

[2]Ruhul kudus su ruanuri ibanil ibanillahi zat muttolak

Potongan lirik lagu di atas merupakan pujian menggunakan bahasa Arab. Frase ya Ilallahu zat muttolakartinya Allah yang memiliki zat mutlak. Pada kedua data ini terdapat pujian yang ditujukan kepada Allah. Penggunaan bahasa Arab dalam syair tarian Aceh, bukanlah suatu yang kebetulan. Syair tari Aceh, pada umumnya memadukan bahasa Aceh dan bahasa Arab.Hal ini dikarenakan tujuan dari tarian ini adalah sebagai media untuk menyampaikan dakwah ajaran Islam. Agar agama Islam mudah diterima masyarakat, maka dakwah yang disampaikan haruslah dalam bentuk yang menarik. Sehingga, banyak shalawat-shalawat dalam bahasa Arab yang dijadikan lirik syair tari Aceh.

Pujian lainnya yang terdapat dalam syair lagu Aceh adalah sebagaimana dalam data berikut: 
[3] Alhamdulillah pujoe bak Tuhan Nyang peujeut Alam Langet ngon Donya (Segala puji bagi Allah, puji-pujian atas Tuhan yang menciptakan Alam langit dan dunia)

[4] Alhamdulillah ya Allah Nyang poe Kuasa (Segala puji bagi Allah, Allahlah yang mempunyai kekuasaan)

[5] Allahu Allah Allahu Rabbi Allah hadiron nyang Maha Suci (Allah..Allah..Allahu Rabbi kehadiran Allah yang Maha Suci)

Pujian-pujianpada data di atas merupakan pujian yang ditujukan kepada Allah, tuhan yang dipercaya umat muslim. Pada data [3] Allah dipuji karena Allahlah yang telah menciptakan langit dan bumi. Selanjutnya, pada data [4], puji-pujian kepada Allah dilakukan karena umat manusia menyadari bahwa Allahlah yang memiliki kuasa atas langit dan bumi. Terakhir, pujian pada data [5] merupakan pujian kepada Allah yang Maha Suci.

Berdasarkan analisis yang terdapat dalam tari rapa'I Aceh, bahwa semua pujian yang ada, ditujukan kepada Allah. Fungsi pujian pada syair tari rapa'I ini merupakan sebagai wujud penghambaan terhadap tuhan yang telah menciptakan semesta berdasarkan isinya.

Hadirnya bentuk pujian yang lebih banyak bahkan semua ditujukan kepada Allah menunjukkan ketundukan orang Aceh terhadap agama Islam. Agama islam dan budaya Aceh sulit dipisahkan. Jika ditinjau dari sejarah, Aceh merupakan tempat masuknya Islam pertama sekali di Indonesia. Berkembangnya ajaran Islam yang sangat pesat di Aceh, menyebabkan Aceh mendapat julukan serambi mekkah. Falsafah hidup orang Aceh yang mengedepankan agama Islam dapat dilihat pada sikap fanatik orang Aceh. Sikap fanatik ini ditunjukkan dengan memakai Islam sebagai landasan terhadap berbuat sesuatu. Masyarakat Aceh dikenal sangat saat pada Al-Quran, Hadits dan perkataan ulama. Ini merupakan bukti ketundukan orang Aceh terhadap Islam. Sehingga, ini tertuang dalam menjalani kehidupan, bahwa Allah lah yang utama.

Demikian pula dengan memuji, orang Aceh menganggap bahwa yang patut dipuji hanya Allah yang memiliki kekuasaan. Hal ini menjawab mengapa pujian terhadap manusia jarang ditemui, karena anggapan bahwa yang patut dipuji hanya Allah yang mencipta.

\section{PENUTUP}

Budaya masyarakat Aceh dapat dilihat dari perilaku berbahasa yang terdapat dalam karya seni. Demikian pula dengan melihat bagaimana suatu masyarakat merespon budaya tertentu, misalnya memuji. Setiap masyarakat dinilai memiliki pandangan 
tertentu terhadap pujian. Namun, tidak semua budaya memandang pujian sama dengan budaya lainnya. Kajian terhadap pujian pada syair tari Rapa'I ini menunjukkan bahwa dalam Syair tari Rapa'I Aceh, pujian umumnya ditujukan kepada Tuhan. Hal ini dikarenakan budaya Aceh yang sangat mengedepankan nilai-nilai Islam sehingga pujian yang ada hanya patut ditujukan pada Tuhan.

\section{DAFTAR PUSTAKA}

\section{$\underline{\text { Buku }}$}

Leech, Geoffrey.1993. Prinsip-prinsip Pragmatik (Diterjemahkan oleh M.D.D. Oka dan Setyadi Setyapranata). Jakarta: Penerbit Universitas Indonesia.

Levinson, Stephen. 1991. Pragmatics. Melbourne Sydney: Cambridge University Press.

Mahsun. 2007. Metode Penelitian Bahasa: Tahapan Strategi, Metode, dan Tekniknya. Jakarta: PT. Raja Grafindo.

Murtala. 2009. Tari Aceh: Yuslizar dan Tari Aceh Yang Mentradisi. Banda Aceh: No Government Individual.

Nadar, F.X. 2009. Pragmatik dan Penelitian Pragmatik. Yogyakarta: Graha Ilmu.

Sudaryanto. 1993. Metode dan Aneka Teknik Analisis Bahasa. Yogyakarta: Duta Wacana University Press.

Yule, George. 1996. Pragmatics. New York: Oxford University Press. 2006. Pragmatik (Diterjemahkan oleh Indah Fajar Wahyuni). Yogyakarta: Pustaka Pelajar.

\section{Jurnal}

Cheng, Dongmei. 2011. “New Insights on Compliment Responses: A Comparison between Native English Speaker and Chinese L2 Speakers". Journal of Pragmatics, Vol.43, pp. 2204-2214. (Online)(http.elsevier.com/locate/pragmatics, diakses 11 Oktober 2017).

Dus, Lorenzo. 2001. "Compliment responses among British and Spanish university students: A Contrastive Study". Journal of Pragmatics, Vol.33, pp. 107-127. (Online)(http.elsevier.com/locate/pragmatics, diakses 11 Oktober 2017). 
Guo, Zhou dan Chow. 2012. "A Variationist Study of Compliment Responses in Chinese". International Journal of Applied Linguistics, Vol.22, No.3, hal. 347- 373. Golato, Andrea. 2002. "German Compliment Responses". Journal of Pragmatics No. 34, hal. 547-571.

Herbert, R. 1986. Say "Thank You" - Or Something. American Speech,61(1), 76-88. doi:10.2307/454710

1990. Sex-Based Differences in Compliment Behavior. Language in Society, 19(2), 201-224. Retrieved from http:// www.jstor.org/stable/4168132

Holmes, Janet. 1986. "Compliments and Compliment Responses in New Zealand English". Antrhopological Linguistics, Vol.28. No.4 (Winter, 1986), pp. 485- 508. (Online)(http//www.jstor.org/stable/30028255, diakses 10 November 2017).

Muhammad, Rusjdi Ali \& Sumardi, Dedy. 2011. Kearifan Tradisional Lokal: Penyerapan Syariat Islam dalam Hukum Adat Aceh, Banda Aceh: Dinas Syariat Islam.

Ricahyono, Sigit. 2015. JavaneseCompliment-Paying andCompliment- Responding: ACulturalDiscourseApproach. Disertasi. Yogyakarta: Universitas Gadjah Mada.

2012. "Javanese Compliment Response "Joke", Problems of Categorizing, Potentials of Intercultural Encounters, and Pedagogical Implications". The Proceedings of the International and Innovation in Language, Literature, Culture, and Language Teaching. P. (192-202). Madiun: IKIP PGRI

Rose, R. Kenneth. 2001. “Compliment and Compliment Responses in Film: Implication for Pragmatics Research and Language Teaching". IRAL, No.39, pp.309-326).

Valdes, Guadalupe and Cecilia Pino. 1981. "Muy a tus ordenes: Compliment Responses among Mexican-American Bilinguals". Language in Society, Vol. 10, No.1 (Apri, 1981), pp 53-72. (Online) (http//www.jstor.org, diakses 11 Oktober 2017).

Wieland, M. 1995. Complimenting Behavior in French/American Cross-Cultural Dinner Conversations. The French Review, 68(5), 796-812. Retrieved from http://www.jstor.org/stable/397851

Wolfson, N. 1981. Compliments in Cross-Cultural Perspective. TESOL Quarterly, 15(2), 117-124. doi: $10.2307 / 3586403$ 